Article

\title{
Reactive Comb Polymer Compatibilized Immiscible PVDF/PLLA Blends: Effects of the Main Chain Structure of Compatibilizer
}

\author{
Xin Yang ${ }^{1}$, Jinxing Song ${ }^{2}$, Hengti Wang ${ }^{1}$, Qingqing Lin ${ }^{1}$, Xianhua Jin ${ }^{2}$, Xin Yang ${ }^{2}$ and \\ Yongjin $\mathrm{Li}^{1, *}$ \\ 1 College of Materials, Chemistry and Chemical Engineering, Hangzhou Normal University, No. 2318 \\ Yuhangtang Rd., Hangzhou 311121, China; yangxin@stu.hznu.edu.cn (X.Y.); \\ hengti-wang@hznu.edu.cn (H.W.); lqq0770709@163.com (Q.L.) \\ 2 Transfar Zhilian Co. Ltd., Hangzhou 311215, China; songjinxing@126.com (J.S.); gfjxh@163.com (X.J.); \\ 11002@etransfar.com (X.Y.) \\ * Correspondence: yongjin-li@hznu.edu.cn; Tel.: +86-57128867026
}

Received: 7 January 2020; Accepted: 13 February 2020; Published: 2 March 2020

\begin{abstract}
The compatibilizer with double comb structure has a superior compatibilizing effect for immiscible polymer blends due to the symmetrical structure on both sides of main chains. Extensive study related to the architectural effects of compatibilizer on the compatibilization has mainly focused on the side chains. We investigated the influence of the compatibilizer-main-chain structure on the compatibilizing effect for immiscible poly(vinylidene fluoride)/poly(L-lactic acid) (PVDF/PLLA) blends. Two reactive-comb compatibilizers with polystyrene (PS) and polymethylmethacrylate (PMMA) as main chains and PMMA as the side chains have been synthesized. PS is immiscible with both PLLA and PVDF, while PMMA is miscible with PVDF. It was found that both compatibilizers can improve the compatibility between the PLLA and PVDF, with different compatibilization effects. In the PVDF/PLLA (50/50) blends, $1 \mathrm{wt} . \%$ poly(styrene-co-glycidyl methacrylate)-graft-poly(methyl methacrylate) (RC-SG) tuned the morphology from the droplet-in-matrix structure to the co-continuous structure, while the blends with poly(methyl methacrylate-co-glycidyl methacrylate)-graft-poly(methyl methacrylate) (RC-MMG) kept the sea-island structure with even $3 \mathrm{wt} . \%$ loading. Moreover, RC-SG induces a wider co-continuous interval range than RC-MMG. The co-continuous structure obtained by RC-SG was also more stable than that by RC-MMG. It was further found that RC-SG-compatibilized PVDF/PLLA blends exhibit higher mechanical properties than the RC-MMG-compatibilized blends.
\end{abstract}

Keywords: comb structure; main chain; compatibilizing effect; co-continuous

\section{Introduction}

Polymer blending has become an important way to prepare new high-performance polymeric materials over the past 40 years [1-5]. However, most commercial polymer blends are immiscible because of their high molecular weights and unfavorable interactions, and, thus, form multiphase structures [6-8]. Consequently, a variety of compatibilizers have been developed and applied for immiscible polymer blends [9-12]. A great quantity of research has indicated that the reactive-comb-like compatibilizers usually exhibit better compatibilizing effects due to the double-comb structures. The double-grafted side chains of the compatibilizers can stabilize the dynamic balance of the neighboring phases at the interface [13-16]. This technique is based on the in-situ formation of double-grafted copolymers at polymer-polymer interface, which substantially lowers interface tension, suppresses particle coalescence, and ultimately exhibits enhanced physical properties [17-20]. 
Considering the compatibilization mechanism of the reactive-comb polymers for a specific blend, the side chains (grafts A and grafts B) of the comb compatibilizers should exhibit high affinity (or specific interactions) with the component of the polymer blends, and, therefore highcompatibilization efficiency can be achieved, as shown in Scheme 1. It is obvious that the side chains take the critical role for the final compatibilization by the respective entanglements of each graft with the molecular chains of the component while the main chain simply bonds to the side chains to form one molecular structure [21-26]. Therefore, investigations have been focused on the length of the side chain and the graft density of the comb compatibilizers effects on the compatibilizations [27-31]. Attention has seldom been paid to the main chain effects on the compatibilization effects. Wang et al. have synthesized a comb-like copolymer with polystyrene (PS) as the main chain, i.e., poly(styrene-co-glycidyl methacrylate)-graft-poly(methyl methacrylate) (P((St-co-GMA)-g-MMA)), and applied it for compatibilizing PVDF/PLLA immiscible blends [32,33]. The epoxide groups of this compatibilizer can react to the terminal carboxyl groups of PLLA during the melt-blending, forming in situ a double-grafted copolymer (i.e., (PLLA-g-PS-g-PMMA)). Interestingly, they found that the PS main chain of the double-grafted copolymer would collapse to form nanomicelles at the PVDF-PLLA interface. The nanomicelles could further self-assemble to create Janus nanomicelles (JNMs) with one side rich in PMMA and the other in PLLA side chains, and thus enhancing the compatibilization. This interfacial JNMs compatibilization was attributed to the unique quality of PS main chain, indicating that the main chain of compatibilizer also plays an indispensable role in compatibilization.

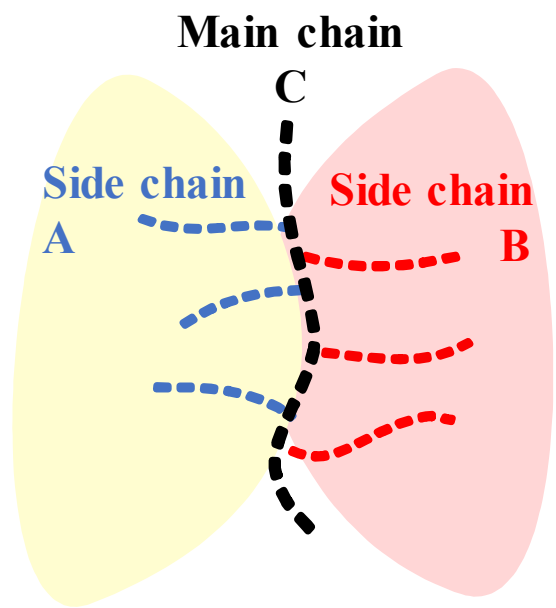

Scheme 1. Schematic diagram of immiscible blends compatibilized by double-grafted compatibilizers.

To clarify the role of main chain of compatibilizer in the compatibilization, we designed two reactive-comb copolymers with almost identical structures, except the main chain, namely poly(styrene-co-glycidyl methacrylate)-graft-poly(methyl methacrylate) (RC-SG) and poly(methyl methacrylate-co-glycidyl methacrylate)-graft-poly(methyl methacrylate) (RC-MMG) by the "grafting through" method. The comparison has been made for the immiscible poly(vinylidene fluoride)/poly(L-lactic acid) (PVDF/PLLA) blends. It was found that both RC-SG and RC-MMG exhibit effective compatibilization effects, but RC-SG easily induces co-continuous structures of the blends and a wider co-continuous interval range than RC-MMG.

\section{Experimental Section}

\subsection{Materials}

The PVDF used in this study was purchased from Kureha Chemicals (Tokyo, Japan). And PLLA was supplied from Nature works (Blair, NE, USA). The reactive copolymers RC-SG or RC-MMG were synthesized by copolymerizing MMA macromer, glycidyl methacrylate (GMA), and St or MMA. 
The specific synthesis routes of RC-SG and RC-MMG are shown in Scheme S1. The ${ }^{1} \mathrm{H}-\mathrm{NMR}$ and IR spectra of RC-MMG is shown in Figure S1. In the ${ }^{1} \mathrm{H}-\mathrm{NMR}$ spectrum, peaks a, c, $d, \mathrm{~g}, \mathrm{~h}$ and i represent MMA characteristic signals; peaks b, e, f are GMA characteristic signals. In Figure S1b, the MMA characteristic peaks $\left(1731 \mathrm{~cm}^{-1}, 1270 \mathrm{~cm}^{-1}, 1243 \mathrm{~cm}^{-1}, 1191 \mathrm{~cm}^{-1}, 1144 \mathrm{~cm}^{-1}\right)$ and epoxy characteristic peak $\left(908 \mathrm{~cm}^{-1}\right)$ appear in the infrared spectrum. Figure S2 shows the ${ }^{1} \mathrm{H}-\mathrm{NMR}$ and IR spectra of RC-SG. In the ${ }^{1} \mathrm{H}-\mathrm{NMR}$ spectrum, peaks $\mathrm{a}, \mathrm{b}$ and $\mathrm{g}$ represent characteristic signals on St; peaks $\mathrm{i}, \mathrm{f}$ and $\mathrm{h}$ represent the characteristic signals of epoxy group; peaks c, $\mathrm{d}$ and e are characteristic signals of MMA macromer. Each peak can also be found in the IR spectrum (Figure S2b), the characteristic absorption peaks near $3000 \mathrm{~cm}^{-1}$ are stretching vibration of $-\mathrm{CH}$ on St; peak $908 \mathrm{~cm}^{-1}$ is epoxy characteristic signal; $1730 \mathrm{~cm}^{-1}, 1270 \mathrm{~cm}^{-1}, 1244 \mathrm{~cm}^{-1}, 1190 \mathrm{~cm}^{-1}$ and $1146 \mathrm{~cm}^{-1}$ are MMA-characteristic absorption bands. Therefore, we confirmed the synthesis of reactive-comb polymers (RC-SG and RC-MMG) with the same structure, except for the main chain.

The nomenclature of the copolymers is as follows: the side chains of the two reactive copolymers are PMMA $\left(M_{n}=4000\right)$ and the reactive compatibilizers contain $20 \mathrm{wt} . \%$ of the GMA monomer. Detailed characteristics of the copolymers used are listed in Table 1.

Table 1. Molecular characteristics of the reactive compatibilizers with various feed ratio.

\begin{tabular}{|c|c|c|c|}
\hline Sample & Experimental Formula (Weight Ratio) & 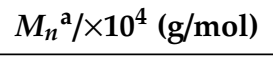 & PDI $^{a}$ \\
\hline RC-SG & $\begin{array}{c}{[\mathrm{St}]:[\mathrm{GMA}]:[\mathrm{MMA} \text { macromer] }} \\
7: 2: 1\end{array}$ & 1.35 & 2.05 \\
\hline RC-MMG & $\begin{array}{c}\text { [MMA]:[GMA]:[MMA macromer] } \\
7: 2: 1\end{array}$ & 1.28 & 2.03 \\
\hline
\end{tabular}

${ }^{\mathrm{a}} M_{n}$ and PDI were determined by Gel permeation chromatography (GPC).

Gel permeation chromatography (GPC) (Wyatt T-rEX, Santa Barbara, CA, USA) was carried out to determine the number-average molecular weights $\left(M_{n}\right)$ and dispersities (Đ) by using two MZ-Gel SD plus $10.0 \mu \mathrm{m}$ bead-size columns $\left(10^{3}\right.$ and $\left.10^{5} \AA\right)$ and Optilab T-rEX detector. THF was used as the mobile phase at a flow rate of $1 \mathrm{~mL} / \mathrm{min}$ at $35^{\circ} \mathrm{C}$. The system was calibrated with narrow molecular weight distribution polystyrene standards from 2000 to $10^{6} \mathrm{~g} / \mathrm{mol}$. The elution diagrams were analyzed using the ASTRA 6 software from Wyatt Technology.

\subsection{Sample Preparation}

All the materials were dried in a vacuum oven at $80^{\circ} \mathrm{C}$ for at least $24 \mathrm{~h}$ before mixing. The PVDF/PLLA (50/50, w/w) blends without and with various RC-SG or RC-MMG contents were produced by melt-blending directly into the batch mixer (Haake Polylab QC), (Thermo Fisher Scientific, Waltham, MA, USA) with a rotation speed of $50 \mathrm{rpm}$ at $190{ }^{\circ} \mathrm{C}$ for $10 \mathrm{~min}$. Subsequently, the resulted blends were compression-molded at $200{ }^{\circ} \mathrm{C}$ under $10 \mathrm{MPa}$ for $5 \mathrm{~min}$ and cooled to $35^{\circ} \mathrm{C}$ by circulating water.

\subsection{Characterization}

\subsubsection{Scanning Electron Microscopy (SEM)}

SEM observations were performed on a field-emission SEM machine (Hitachi S-4800, Tokyo, Japan) operated at a voltage of $5 \mathrm{kV}$. Before the observation, the entire specimens were cryo-fractured in liquid nitrogen. Then, the specimens were coated with gold by plasma deposition.

\subsubsection{Transmission Electron Microscopy (TEM)}

To detect the structure and distribution of RC-SG or RC-MMG, reactive-blended samples were observed by a transmission-electron microscopy system (Hitachi HT-7700, Tokyo, Japan) operated at 
an accelerating voltage of $100 \mathrm{kV}$. All samples were stained by $\mathrm{RuO}_{4}$ for $4 \mathrm{~h}$ to enhance the contrast before the TEM observation.

\subsubsection{Mechanical Properties}

Charpy impact tests were performed according to GB/T 16420-1996 standard on an impact tester (Sartec SS-3700, Taiwan, China). The samples are molded by an injection-molding machine with the size of $80.0 \times 10.0 \times 4.0 \mathrm{~mm}^{3}$. The tensile testing was on an Instron universal-material testing-system (Instron, Norwood, MA, USA) at room temperature, and the tension rate was $10 \mathrm{~mm} / \mathrm{min}$. The specimens were punched out into dumbbell shapes, with the size of $18 \mathrm{~mm}, 3 \mathrm{~mm}, 0.5 \mathrm{~mm}$ (length, width, thickness). All tensile and impact results are shown in Table S1.

\subsubsection{Dynamic Mechanical Analysis (DMA)}

DMA was carried out using DMA Q-800 (TA Instrument, New Castle, PA, USA) under a nitrogen atmosphere. Firstly, the sample was cut up into a size of $8 \mathrm{~mm}, 6.3 \mathrm{~mm}, 0.5 \mathrm{~mm}$ (length, width, thickness). Then, all specimens were tested at a frequency of $5 \mathrm{~Hz}$, an amplitude of $4 \mu \mathrm{m}$, and a heating rate of $10^{\circ} \mathrm{C} / \mathrm{min}$ from -50 to $200{ }^{\circ} \mathrm{C}$.

\section{Results}

\subsection{Morphologies}

To investigate the influence of RC-SG and RC-MMG as compatibilizers on the morphology of immiscible PVDF/PLLA blends, the fracture surfaces of samples were analyzed by SEM, as shown in Figure 1. For the pure PVDF/PLLA (50/50) blend, PVDF forms domains that disperse in the PLLA matrix (Figure 1a) due to the much higher melt viscosity and density of PVDF than of PLLA. The PVDF/PLLA system is a classic thermodynamic immiscible blend. The PVDF domain size varies from 5 to $50 \mu \mathrm{m}$, indicating a high-interfacial tension between the phases. Besides, some clear gaps were observed at the PVDF-PLLA interface for their weak interfacial adhesion. When 0.5 wt.\% RC-SG was added, the PVDF domains became more refined, with number-average diameters about $2.5 \mu \mathrm{m}$, indicating the effective compatibilization effects of RC-SG. Continuingly increasing the dosage of RC-SG, the morphology of the mixture has changed from a sea-island structure to a co-continuous structure at $1 \mathrm{wt}$ \% loading. Similarly, the size of PVDF droplet decreases with the increasing RC-MMG content, and the interfacial adhesion between the phases becomes stronger. This means that RC-MMG is also a good compatibilizer for the PVDF/PLLA blends. However, as opposed to the blends compatibilized by RC-SG, the PLLA/PVDF blends keep the typical sea-island structure, even with 3 wt.\% loading. The domain size decreases continuously with increasing RC-MMG loadings. Therefore, it is concluded that both RC-SG and RC-MMG compatibilize the PVDF/PLLA blends effectively, while the compatibilization modes differ. It is obvious that the epoxide groups on the main chain can react with the end-carboxylic groups of PLLA during the melt-blending, and the double grafts form to compatibilize the blends. The side chain and epoxy content of RC-SG and RC-MMG are equal, except for the trunk chain. It is indicated that the significant main-chain functions during compatibilizing the immiscible PVDF/PLLA system with almost the same side chains.

Figure 2 shows the fractured surfaces of PVDF/PLLA blends at different components with and without 1 wt.\% compatibilizer. For PVDF/PLLA blends without compatibilizers, only the PVDF/PLLA $(65 / 35)$ blend is a co-continuous structure and the phase size is about $30 \mu \mathrm{m}$ (Figure $2 \mathrm{~b}$ ). It must be noted that the figure magnification of this blend is not equal to other compatibilized blends due to its large co-continuous phase size. The co-continuous interval does not change at all with the addition of 1 wt. $\%$ RC-MMG. However, for PVDF/PLLA blends compatibilized with $1 \mathrm{wt}$.\% RC-SG, a wider co-continuous interval from PVDF/PLLA $=50 / 50$ to 75/25 was identified, as shown in Figure 3 . The significant expansion of the co-continuous interval can be clearly observed for the RC-SG-compatibilized blends, as compared with the blends without compatibilizers or compatibilized by RC-MMG. 

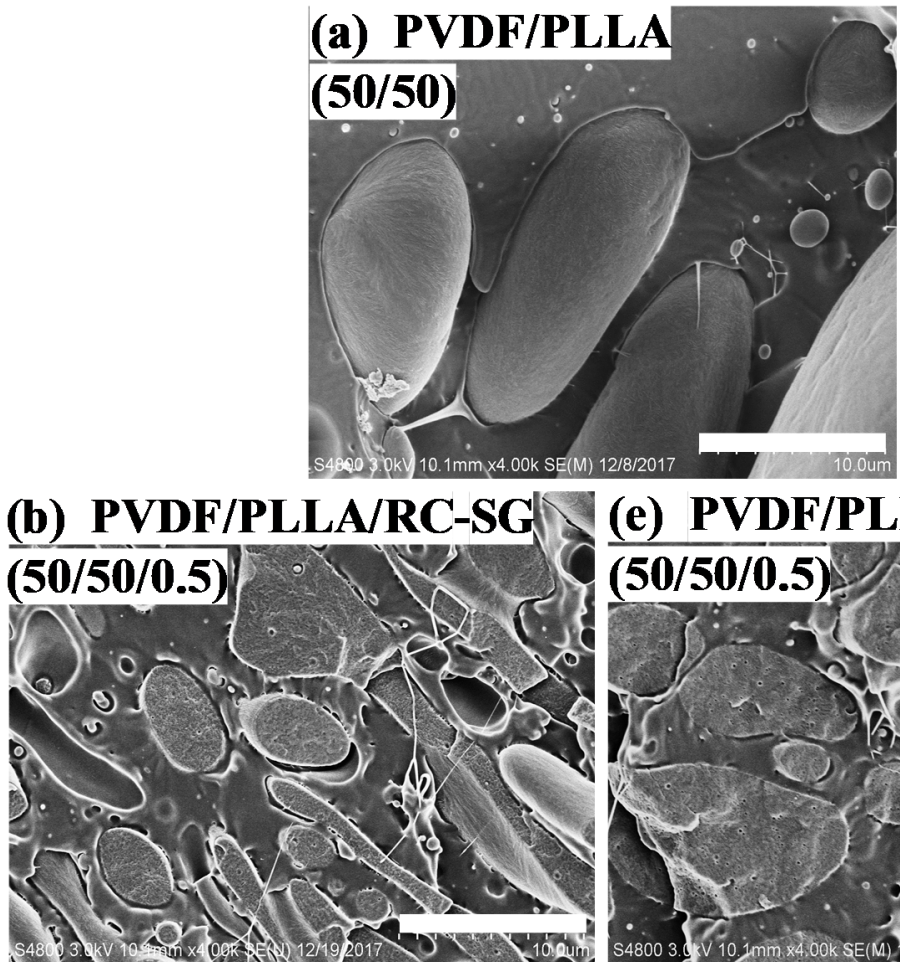

(e) PVDF/PLLA/RC-MMG
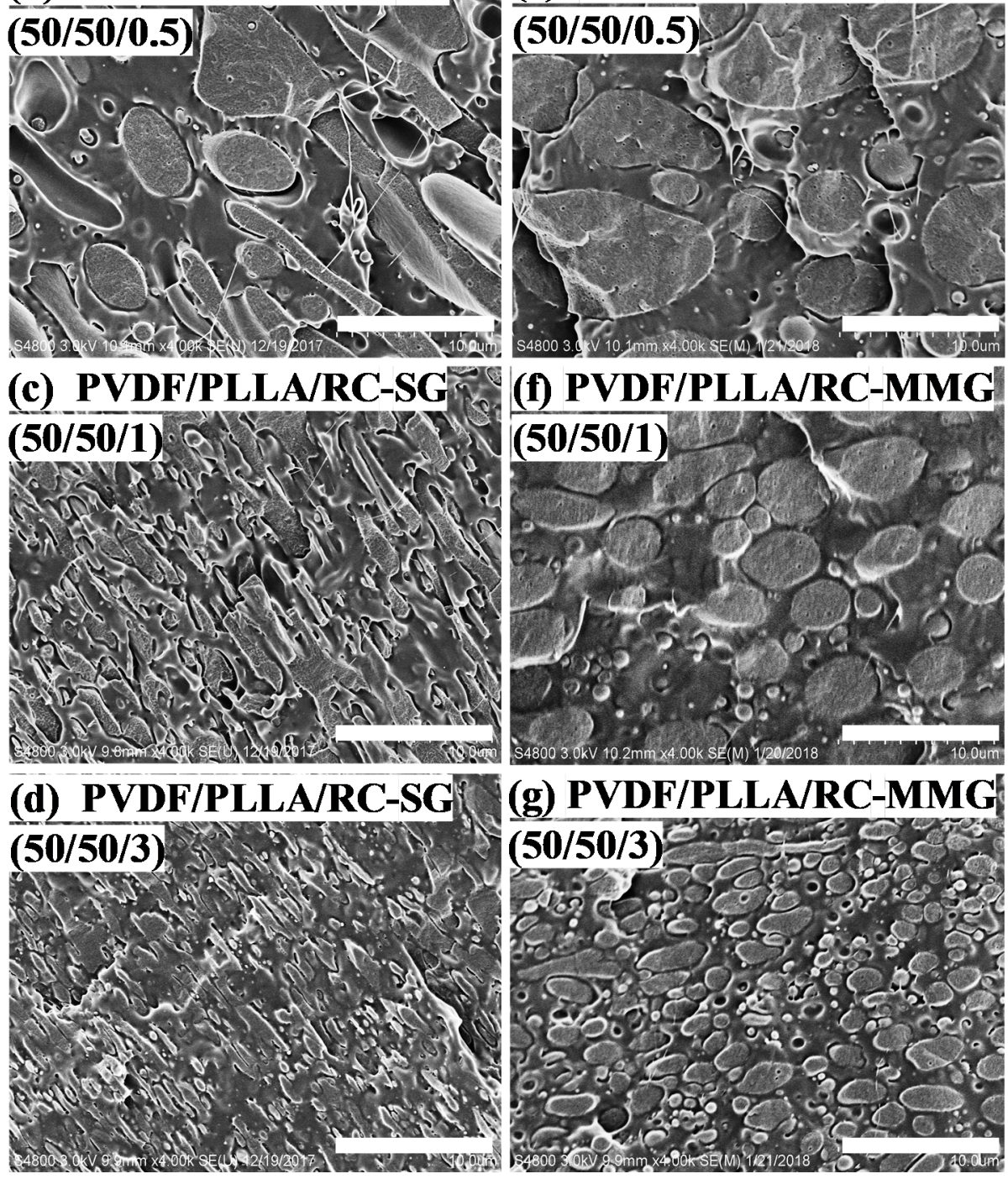

Figure 1. SEM micrographs of PVDF/PLLA (50/50, w/w) blends with various RC-SG or RC-MMG contents: (a) 0 wt.\% compatibilizer, (b-d) 0.5 wt. $\%, 1$ wt. $\%$ and 3 wt. $\%$ RC-SG, (e-g) 0.5 wt. \%, 1 wt. \% and $3 \mathrm{wt} . \%$ RC-MMG. The white bar denotes $10 \mu \mathrm{m}$. 

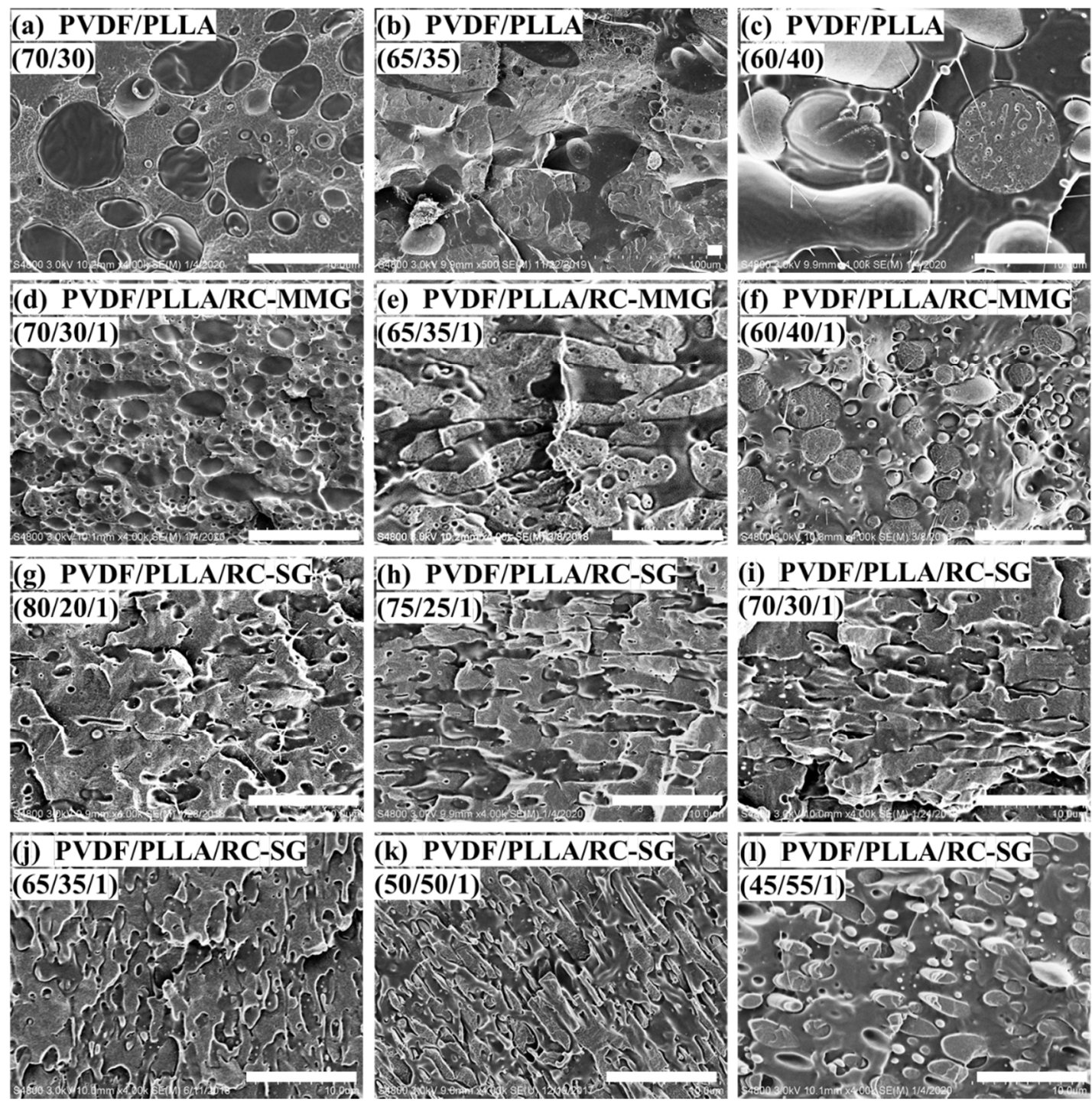

Figure 2. SEM photos of various PVDF/PLLA blends without and with 1 wt.\% compatibilizer: (a-c) 0 wt.\% compatibilizer, (d-f) 1 wt.\% RC-MMG, (g-1) 1 wt.\% RC-SG. The white bar denotes $10 \mu \mathrm{m}$.

The morphology of highly immiscible polymer blends is not stable due to the phase coalescence in the melt state [34,35]. Such coalescence is originated from the high-interfacial tension between the phases. Therefore, the morphological stability of polymer blends in melt indicates the effects of the compatibilizers, and this can usually be confirmed by the annealing experiments [36,37]. The thermal stabilities of the co-continuous morphology of the PVDF/PLLA (65/35) blends with 1\% RC-SG and RC-MMG as compatibilizers are compared in Figure 4. All samples were annealed under vacuum at 200 ${ }^{\circ} \mathrm{C}$ for $1 \mathrm{~h}$ under static conditions. For PVDF/PLLA/RC-MMG (65/35/1) blend, the phase morphology has changed greatly from the original co-continuous structure to the sea-island structure, indicating the poor interfacial stability (Figure $4 \mathrm{a}_{1} \mathrm{a}_{1}$ ). In contrast, there was little change to the structure of the PVDF/PLLA (65/35) blend compatibilized by RC-SG after annealing, as evidenced in Figure $4 b, b_{1}$. This means that the blend with RC-SG has better interfacial stability and the co-continuous structure is stable upon the annealing. Favis et al. have illustrated the morphology evolution of the co-continuous blends during annealing [38]. The driving force of coarsening during annealing is the capillary pressure from the minor phase domains, which is proportional to the interfacial tension. Due to the lower interfacial tension of the blend with RC-SG than that with RC-MMG, it exhibits a superior thermal stability. All the morphological analysis indicates that the RC-SG induces the co-continuous structure and the formed morphology is more stable than RC-MMG. 


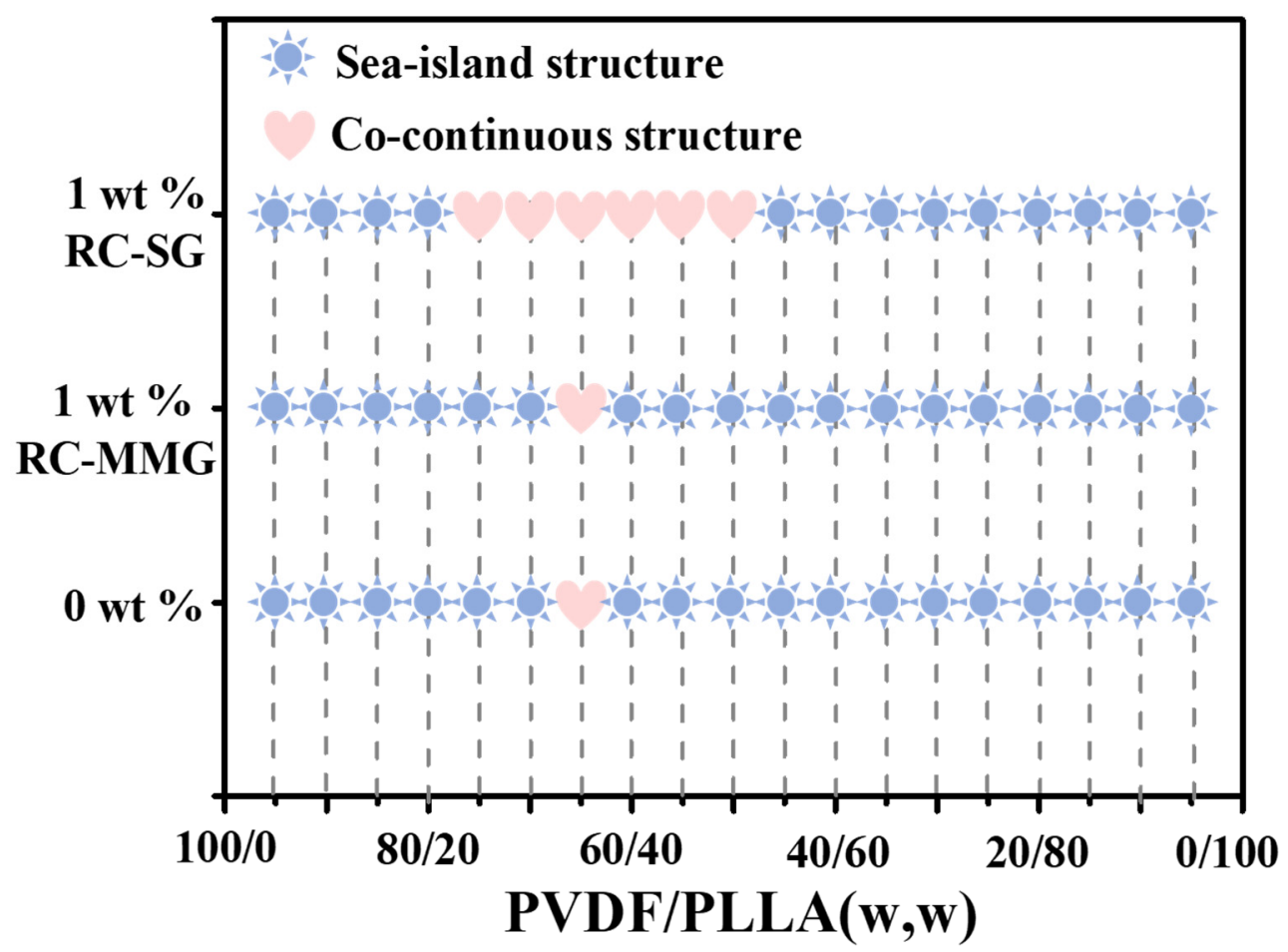

Figure 3. Co-continuous structure of PVDF/PLLA blends as functions of the compositions with and without compatibilizers.

(a) PVDF/PLLA/RC-MMG
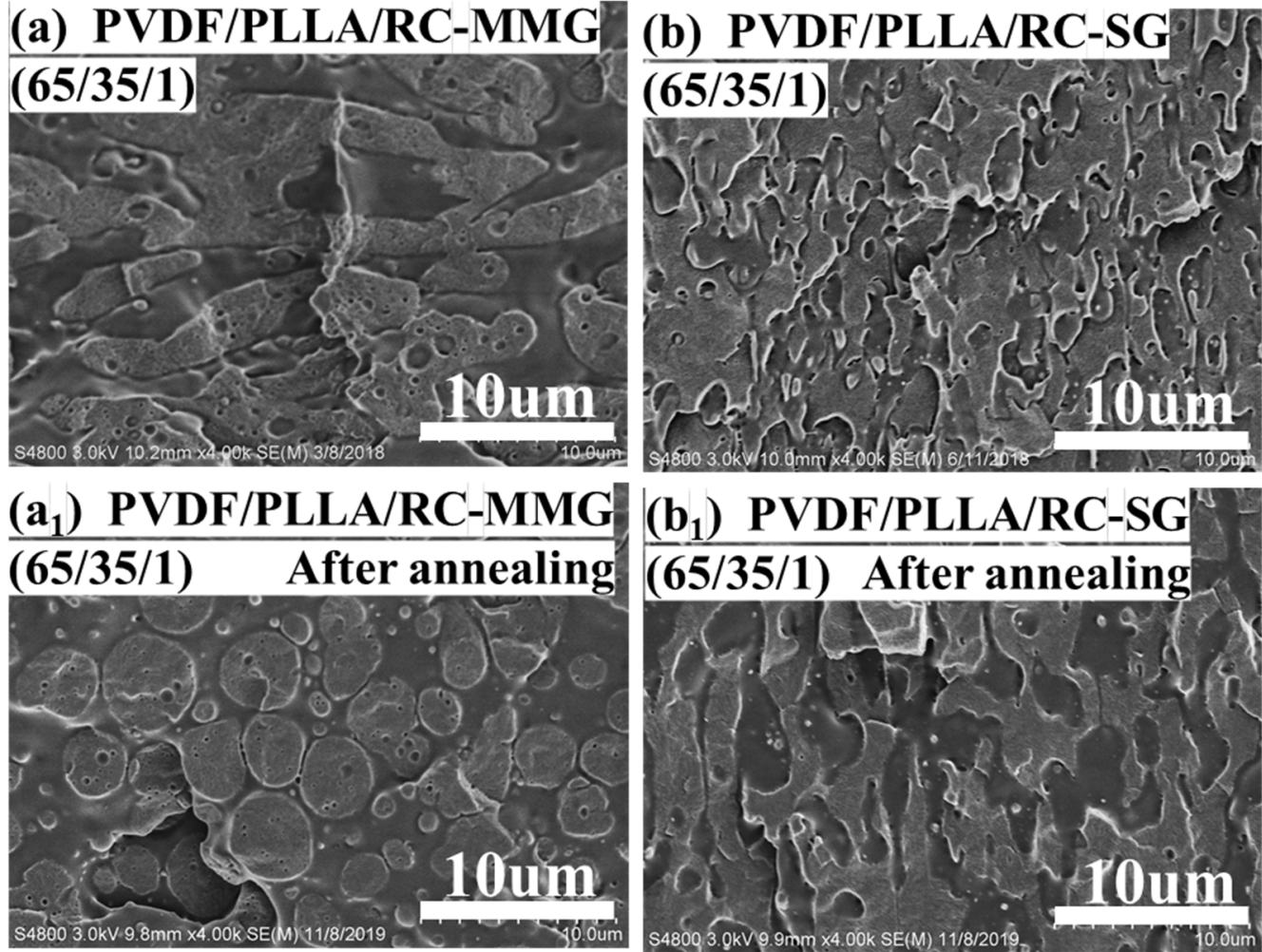

Figure 4. SEM images of PVDF/PLLA (65/35, w/w) blends with 1 wt.\% RC-MMG (a,a 1 ) or RC-SG $\left(\mathbf{b}, \mathbf{b}_{\mathbf{1}}\right)$ before and after annealing. 


\subsection{Mechanical Properties}

Figure 5 reveals the mechanical properties of the representative samples compatibilized by RC-SG and RC-MMG. Markedly enhanced ductility is observed for the PVDF/PLLA blend containing RC-SG and RC-MMG (Figure 5a). The elongation at break of the PVDF/PLLA (50/50) blend without any compatibilizer is $3.6 \%$, compared with $159.0 \%$ for the blend with $0.5 \mathrm{wt} . \%$ RC-SG and $109.7 \%$ for the sample with equivalent RC-MMG content. Continuingly increasing the dosage of compatibilizers to 3 wt. $\%$, the elongation at break of RC-SG- and RC-MMG-mixed samples have reached to $340.4 \%$ and $408.4 \%$, respectively (Table S1). Moreover, the breaking strength of RC-SG-compatibilized blends is also much higher than the blend with the equal addition of RC-MMG. For example, the breaking strength of the blend with $1 \mathrm{wt} . \%$ RC-SG is $46.1 \mathrm{MPa}$, while the value for RC-MMG-compatibilized blend is only 37.6 MPa. Impact toughness refers to the ability of materials to absorb plastic deformation work and fracture work under impact loading, reflecting the tiny defects and impact resistance of materials. The impact strength of the compatibilized blends is shown in Figure 5b. Both RC-SG and RC-MMG can significantly improve the impact toughness of PVDF/PLLA blend, but RC-SG always works better than RC-MMG. Such as the blends with 3 wt.\% compatibilizers, the impact strength of PVDF/PLLA/RC-SG blend is $41.5 \mathrm{~kJ} / \mathrm{m}^{2}$ while the value of RC-MMG-compatibilized blend is only $33.0 \mathrm{~kJ} / \mathrm{m}^{2}$. This might be attributed to the co-continuous structure induced by the RC-SG compatibilizer, as shown in Figure 1 . It is widely acknowledged that the co-continuous structure helps to significantly improve interfacial interactions and effectively promoting stress transfer [39]. It is also the reason for the better tensile behavior of the blend mixed with RC-SG than the RC-MMG-compatibilized blend.

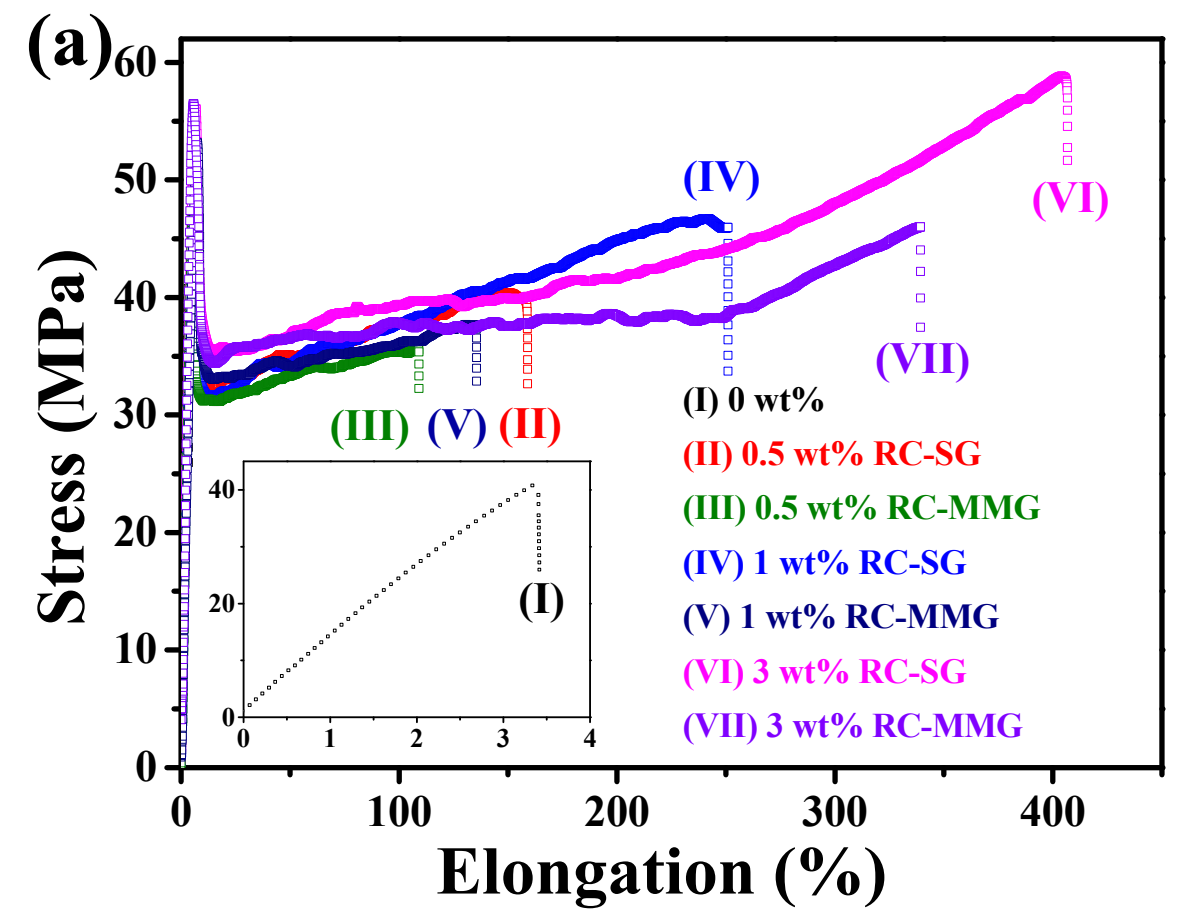

Figure 5. Cont. 


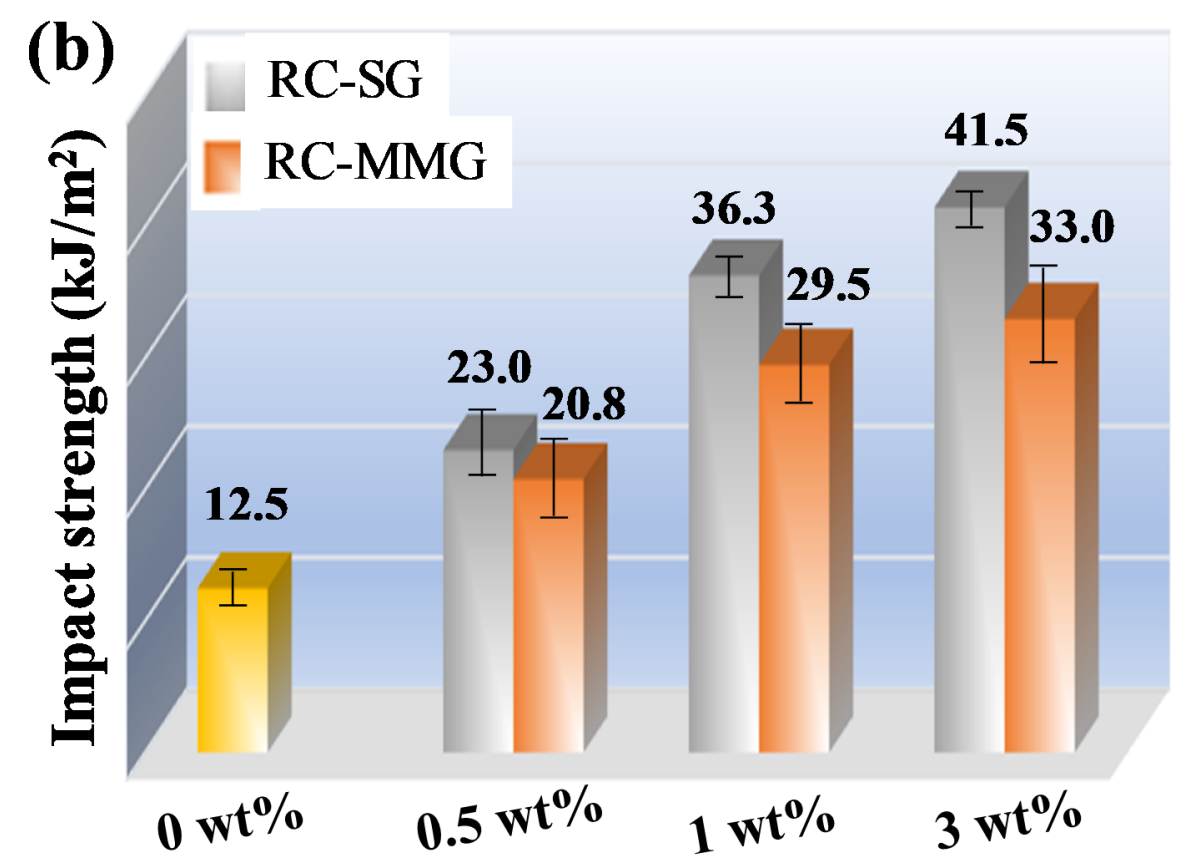

Figure 5. (a) Stress-elongation curves and (b) impact strength of PVDF/PLLA (50/50,w/w) blends with various contents of RC-SG or RC-MMG.

\subsection{Dynamic Mechanical Analysis}

The DMA measurements were carried out for PVDF/PLLA (50/50) blends containing various types of compatibilizers. Figure 6 shows the storage modulus $\left(\mathrm{E}^{\prime}\right)$ and $\tan \delta$ as a function of the temperature. As shown in Figure 6a, the storage modulus decreases abruptly at $53{ }^{\circ} \mathrm{C}$ owing to the glass transition of PLLA for the all blends, followed by an increase of $\mathrm{E}^{\prime}$ originating from the cold crystallization of PLLA during heating, as evidenced by DSC curves (Figure S3). Significant difference can be observed for the storage modulus values at the temperature just above the $T_{\mathrm{g}}$ of PLLA. The RC-SG-compatibilized blends exhibit significantly higher storage modules than the RC-MMG-compatibilized blends in the temperature ranging from 60 to $100{ }^{\circ} \mathrm{C}$, indicating the higher heat resistance of the RC-SG-compatibilized sample. This is attributed to the co-continuous microstructure of the blends. The PVDF and PLLA phases are co-continuous owing to the emulsifying effect of RC-SG. Thereby, the continuous PVDF parts still can support the blend even PLLA segments become soft above its $T_{\mathrm{g}}$. In contrast, both binary PVDF/PLLA blend and RC-MMG-compatibilized blend are the sea-island morphology with PLLA as the matrix. Therefore, both samples show lower storage modulus in the temperature region of PLLA glass transition. It should be noted that the blend without compatibilizer has a higher storage modulus than the RC-MMG-compatibilized blend. The mechanism of such difference is not clear, but it is clear that the modulus would be dependent on the domain size and domain size distribution for sea-island morphology. On the other hand, it is also seen that RC-SG induces the decreasing of the glass transition temperatures of PLLA and RC-MMG does not lead to the significant changes (Figure $6 \mathrm{~b}$ ). We used the DMA data of the samples with 1 $\mathrm{wt} . \%$ compatibilizer to demonstrate the fact that very low compatibilizers $(1 \mathrm{wt} . \%)$ improves the heat resistance of the blend due to the formation of co-continuous structure. In fact, the samples with a higher content of compatibilizers ( $3 \mathrm{wt} . \%)$ demonstrate similar results, as shown in Supporting Information Figure S4. 

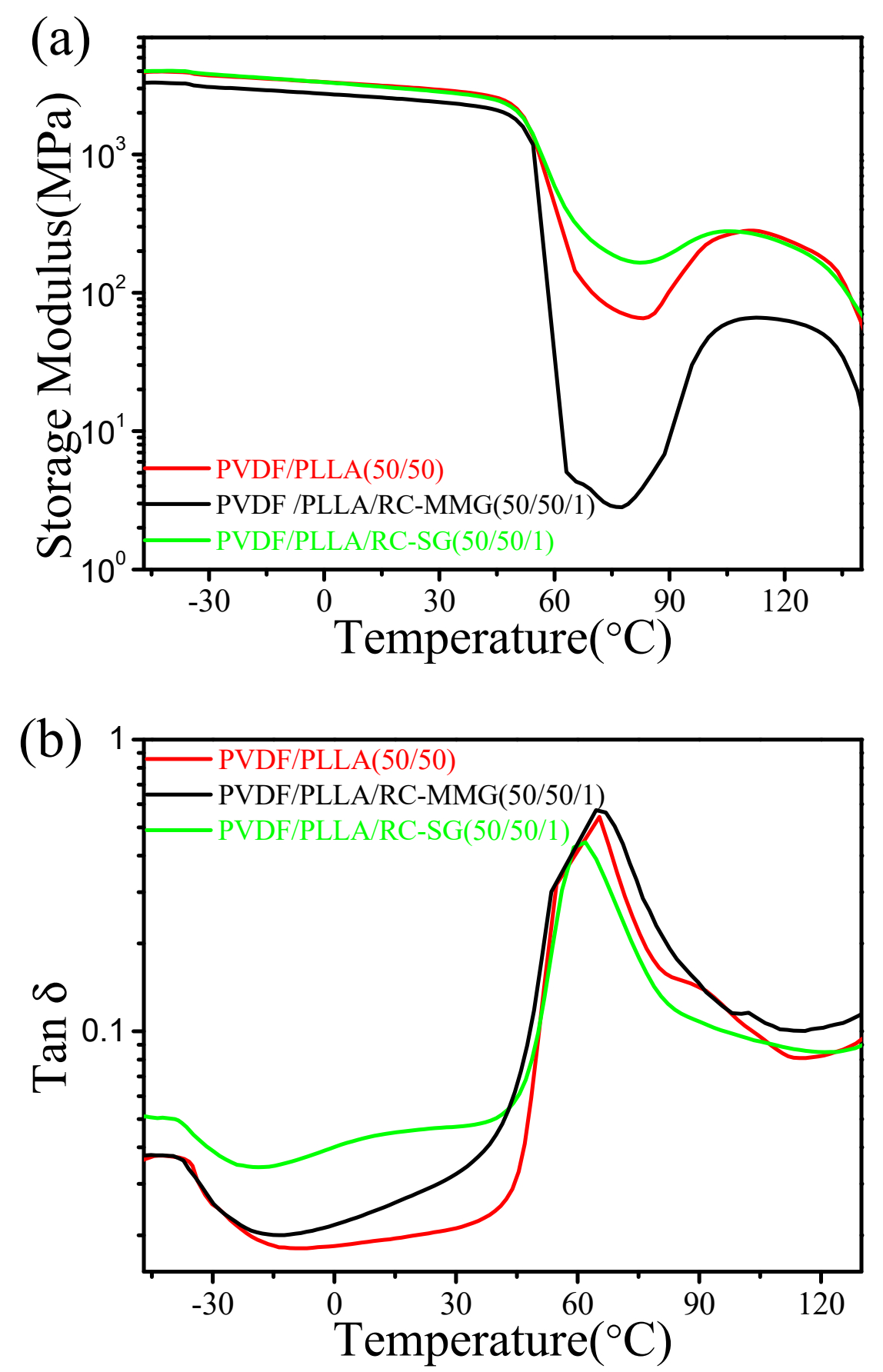

Figure 6. (a) Storage modulus and (b) loss tangent (tan delta) as a function of temperature with a frequency of $5 \mathrm{~Hz}$ for PVDF/PLLA (50/50, w/w) blend and compatibilized blends.

\section{Discussion}

It is concluded that both RC-SG and RC-MMG play the role of effective compatibilizers for PVDF/PLLA blends. They have not only the same PMMA side chains, but also similar reactivity - grafting the same amount of PLLA chains in melt-blending — thus resulting in double-graft copolymers PMMA- $g$-MMG- $g$-PLLA and PMMA- $g$-SG- $g$-PLLA, except the main chains. The PMMA and PLLA side chains of both PMMA-g-MMG-g-PLLA and PMMA-g-SG-g-PLLA can entangle with the PVDF and PLLA phase, respectively, so they can easily locate at the PVDF-PLLA interface and improve the compatibility of PVDF/PLLA blends. However, it is interesting to find that RC-SG can easily induce the stable co-continuous structure, as compared with RC-MMG. Moreover, better mechanical properties 
were achieved for the RC-SG-compatibilized blends with the co-continuous structure. In order to elucidate the different compatibilization mechanisms of the two compatibilizers with different main chains, more detailed morphological information was obtained by TEM, as shown in Figure 7. PVDF is observed as the black part, and PLLA corresponds to the white part, because PLLA is harder to be stained by $\mathrm{RuO}_{4}$ than PVDF. Clearly, PVDF forms spherical domains dispersed in the PLLA matrix for the RC-MMG-compatibilized blends. The interface is clean and sharp for the RC-MMG-compatibilized blends. In contrast, the RC-SG compatibilized blends show the elongated PVDF phase, indicating the typical co-continuous structure. In particular, such co-continuous structure means that the interface curvature is very small (or even a straight interface) for the RC-SG-compatibilized blends. We consider that the different interface curvature originates from the different main-chain structures of the two compatibilizers. PLLA chains were grafted onto the main chain of the compatibilizers during the reactive blending, so the binary grafted compatibilizers with PMMA side chains and PLLA side chains were formed as the compatibilizers for the PLLA/PVDF blends. Both compatibilizers are located at the interface through the respective entanglements (or interactions) of PLLA side chains with PLLA chains in PLLA phase and PMMA side chains with PVDF chains in PVDF phase, as shown in Scheme 2. Therefore, both RC-SG and RC-MMG play an effective role in compatibilizing the PVDF/PLLA blends. However, the different main chains of the compatibilizers lead to totally different interface curvatures of the blends and subsequent different morphologies of the final blends. For the final PMMA- $g$-SG- $g$-PLLA compatibilizers, the PS main chain was rejected by both PLLA and PVDF chains because PS shows neither interactions with PLLA nor interactions with PVDF. This is evidenced by the high immiscibility of PS/PLLA blends [40] and PS/PVDF blends [41,42]. Therefore, the PS main chain is pulled by PMMA and PLLA side chains in opposite directions, and the PS main chains form the straight conformation, as shown in Scheme $2 b$. Therefore, the co-continuous morphology with the straight interface can be easily obtained. In contrast, the PMMA main chains of the RC-MMG compatibilizers show highly specific interactions with PVDF phase as the side PMMA chains, so the interface with high curvatures is formed and the typical sea-island morphology is obtained. It should be noted that some very small micelles can be observed in the PLLA phase for RC-SG-compatibilized blends in Figure $7 \mathrm{~b}$. This originates from the unbalanced PLLA side chains and PMMA side chains of the final double-grafted molecules and such molecules were pulled into the PLLA phases. Wang et al. have synthesized similar comb-like molecules with PS main chain and PMMA side chains $\left(M_{n}\right.$ $=2000$ ) as compatibilizers for PVDF/PLLA blends [33]. It was found that the PS main chain of their compatibilizer collapsed to form nanomicelles at the PVDF-PLLA interface. In present work, the RC-SG has longer PMMA side chains $\left(M_{n}=4000\right)$. It is considered that long side PMMA chains lead to the strong entanglements with the PVDF chains and few small micelles were observed.
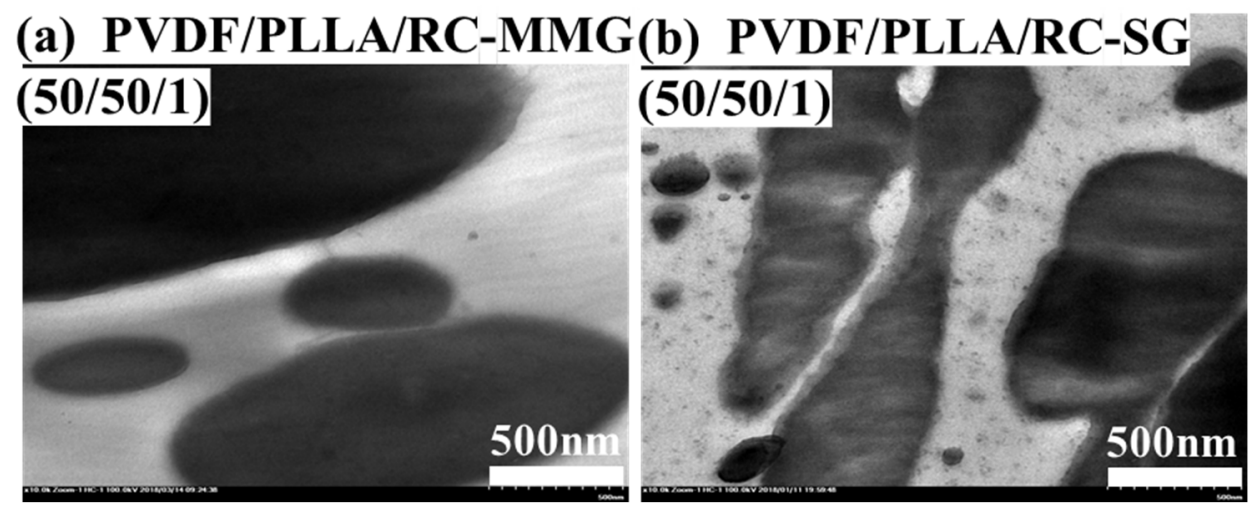

Figure 7. TEM images of PVDF/PLLA (50/50, w/w) blends with 1 wt.\% RC-MMG (a) or RC-SG (b). 


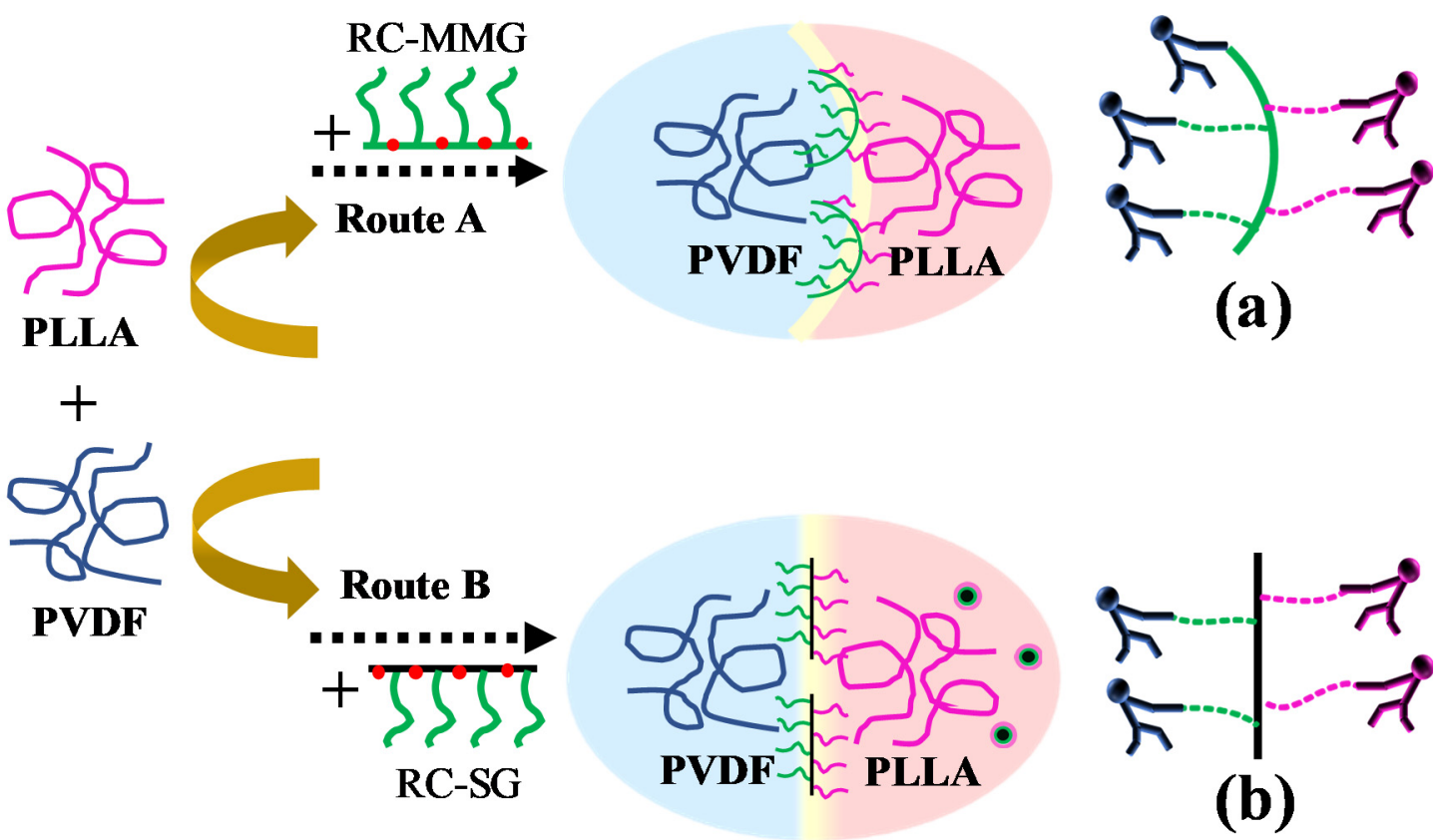

Scheme 2. Schematic diagrams of the compatibilization mechanism of PVDF/PLLA blend by RC-SG or RC-MMG.

\section{Conclusions}

Reactive-comb polymers with PS and PMMA main chains have been synthesized and used as the compatibilizers for the PVDF/PLLA blends. Both reactive-comb polymers exhibited drastic compatibilization effects of the blends with decreased phase size and enhanced mechanical properties. The PVDF-PLLA interface produced by RC-SG was straight due to the binary repulsion of the two side chains, helping to induce stable co-continuous morphologies. The blends with a co-continuous structure exhibited high ductility, excellent impact strength and good heat resistance.

Supplementary Materials: The following are available online at http://www.mdpi.com/2073-4360/12/3/526/s1, Scheme S1: Additional data for synthesis routes of RC-SG and RC-MMG; Figure S1: ${ }^{1} \mathrm{H}-\mathrm{NMR}$ and IR spectrum of RC-MMG; Figure S2: ${ }^{1} \mathrm{H}-\mathrm{NMR}$ and IR spectrum of RC-SG; Figure S3: DSC curves of PVDF/PLLA (50/50) blend without and with various compatibilizers; Figure S4: DMA curves of PVDF/PLLA (50/50) blend without and with various compatibilizers; Table S1: Mechanical properties for PVDF/PLLA blends with and without compatibilizers.

Author Contributions: Conceptualization, Y.L.; methodology, X.Y.1; software, X.Y.1 and J.S.; validation, X.Y.1 and Y.L.; formal analysis, H.W. and Q.L.; investigation, X.Y.1; resources, J.S., X.J. and X.Y.1; data curation, X.Y.1 and Q.L.; writing - original draft preparation, X.Y.1; writing - review and editing, X.Y.2 and Y.L.; visualization, X.Y.1; supervision, X.Y.2 and Y.L.; project administration, Y.L.; funding acquisition, Y.L. All authors have read and agreed to the published version of the manuscript.

Funding: This work is supported by National Key R\&D Program of China (2017YFB0307704), Zhejiang Natural Science foundation (LD19E030001) and National Natural Science Foundation of China (21674033).

Conflicts of Interest: The authors declare no conflict of interest.

\section{References}

1. Han, D.; Wen, T.J.; Han, G.; Deng, Y.Y.; Deng, Y.; Zhang, Q.; Fu, Q. Synthesis of Janus POSS star polymer and exploring its compatibilization behavior for PLLA/PCL polymer blends. Polymer 2018, 136, 84-91. [CrossRef]

2. Gottlieb, L.; Greenfeld, H.; Blumer-Ganon, B. In-situ compatibilization of an immiscible liquid hydroxyl-terminated polymer pair by rate controlled reactions with a diisocyanate. Polymer 2018, 138, 320-328. [CrossRef]

3. Wang, J.; Tsou, A.H.; Passino, H.L.; Favis, B.D. PPE-g-HDPE in high-performance Poly(p-Phenylene ether)/polyethylene blends: Synthesis and compatibilization effects. Polymer 2018, 138, 92-102. [CrossRef] 
4. Zuo, X.H.; Xue, Y.; Wang, L.K.; Zhou, Y.C.; Yin, Y.F.; Chuang, Y.; Chang, C.; Yin, R.; Rafailovich, M.; Guo, Y.C. Engineering styrenic blends with poly(lactic acid). Macromolecules 2019, 52, 7547-7556. [CrossRef]

5. Rohde, B.; Culp, T.; Gomez, E.; Ilavsky, J.; Krishnamoorti, R.; Robertson, M. Nanostructured thermoset/thermoset blends compatibilized with an amphiphilic block copolymer. Macromolecules 2019, 52, 3104-3114. [CrossRef]

6. Liu, H.; Chen, N.; Shan, P.; Song, P.; Liu, X.; Chen, J. Toward fully bio-based and supertough PLA blends via in situ formation of cross-linked biopolyamide continuity network. Macromolecules 2019, 52, 8415-8429. [CrossRef]

7. Lee, S.; Kim, M.; Song, H.; Hyun, K. Characterization of the effect of clay on morphological evaluations of PLA/biodegradable polymer blends by FT-Rheology. Macromolecules 2019, 52, 7904-7919. [CrossRef]

8. Deng, S.; Bai, H.; Liu, Z.; Zhang, Q.; Fu, Q. Toward supertough and heat-resistant stereocomplex-type polylactide/elastomer blends with impressive melt stability via in situ formation of graft copolymer during one-pot reactive melt blending. Macromolecules 2019, 52, 1718-1730. [CrossRef]

9. Todd, A.D.; McEneany, R.J.; Topolkaraev, V.A.; Macosko, C.W.; Hillmyer, M.A. Reactive compatibilization of poly(ethylene terephthalate) and high-density polyethylene using amino-telechelic polyethylene. Macromolecules 2016, 49, 8988-8994. [CrossRef]

10. Trifkovic, M.; Hedegaard, A.T.; Sheikhzadeh, M.; Huang, S.; Macosko, C.W. Stabilization of PE/PEO cocontinuous blends by interfacial nanoclays. Macromolecules 2015, 48, 4631-4644. [CrossRef]

11. Zhang, J.B.; Lodge, T.P.; Macosko, C.W. Interfacial morphology development during PS/PMMA reactive coupling. Macromolecules 2005, 38, 6586-6591. [CrossRef]

12. Bell, J.R.; Chang, K.; López-Barrón, C.R.; Macosko, C.W.; Morse, D.C. Annealing of cocontinuous polymer blends: Effect of block copolymer molecular weight and architecture. Macromolecules 2010, 43, 5024-5032. [CrossRef]

13. Lebovitz, A.H.; Khait, K.; Torkelson, J.M. In situ block copolymer formation during solid-state shear pulverization: An explanation for blend compatibilization via interpolymer radical reactions. Macromolecules 2002, 35, 9716-9722. [CrossRef]

14. Kim, J.; Gray, M.K.; Zhou, H.Y.; Nguyen, S.T.; Torkelson, J.M. Polymer blend compatibilization by gradient copolymer addition during melt processing: Stabilization of dispersed phase to static coarsening. Macromolecules 2005, 38, 1037-1040. [CrossRef]

15. Wang, M.J.; Yuan, G.C.; Han, C.C. Influences of hyperbranched polyethylenimine on the reactive compatibilization of polycarbonate/polyamide blends. Chin. J. Polym. Sci. 2015, 33, 652-660. [CrossRef]

16. Qin, S.X.; Yu, C.X.; Chen, X.Y.; Zhou, H.P.; Zhao, L.F. Fully biodegradable poly(lactic acid)/poly(propylene carbonate) shape memory materials with low recovery temperature based on in situ compatibilization by dicumyl peroxide. Chin. J. Polym. Sci. 2018, 36, 783-790. [CrossRef]

17. Worasak, P.; Varaporn, T.; Neeranuch, P. Synergistic effect of nucleation and compatibilization on the polylactide and poly(butylene adipate-co-terephthalate) blend films. Chin. J. Polym. Sci. 2016, 34, 1129-1140.

18. Phetwarotai, W.; Phusunti, N.; Aht-Ong, D. Preparation and characteristics of poly(butylene adipate-co-terephthalate)/polylactide blend films via synergistic efficiency of plasticization and compatibilization. Chin. J. Polym. Sci. 2019, 37, 68-78. [CrossRef]

19. Panigrahi, H.; Sreenath, P.R.; Bhowmick, A.K.; Kumar, K.D. Unique compatibilized thermoplastic elastomer from polypropylene and epichlorohydrin rubber. Polymer 2019, 183, 121866. [CrossRef]

20. Li, F.; Zhang, Y.; Zhao, X.W.; Chen, Q.; Li, Y.J.; You, J.C. Graft Ratio: Quantitative measurement and direct evidence for its blending sequence dependence during reactive compatibilization in PVDF/PLLA. Polymer 2019, 185, 121970. [CrossRef]

21. Gere, D.; Czigany, T. Future trends of plastic bottle recycling: Compatibilization of PET and PLA. Polymer 2019, 81, 106160. [CrossRef]

22. Jubinville, D.; Chang, B.P.; Pin, J.M.; Mohanty, A.K.; Misra, M. Synergistic thermo-oxidative maleation of PA11 as compatibilization strategy for PA6 and PBT blend. Polymer 2019, 179, 121594. [CrossRef]

23. Yang, X.; Wang, H.T.; Chen, J.L.; Fu, Z.A.; Zhao, X.W.; Li, Y.J. Copolymers containing two types of reactive groups: New compatibilizer for immiscible PLLA/PA11 polymer blends. Polymer 2019, 177, 139-148. [CrossRef] 
24. Wei, B.; Lin, Q.Q.; Zheng, X.; Gu, X.Y.; Zhao, L.; Li, J.C.; Li, Y.J. Reactive splicing compatibilization of immiscible polymer blends: Compatibilizer synthesis in the melt state and compatibilizer architecture effects. Polymer 2019, 185, 121952. [CrossRef]

25. Chen, D.P.; Wang, H.T.; Li, Y.J. Reactive compatibilization: Formation of double-grafted copolymers by in situ binary grafting and their compatibilization effect. ACS Appl. Mater. Interfaces 2017, 9, 33091-33099. [CrossRef]

26. Wang, H.T.; Fu, Z.A.; Zhao, X.W.; Li, Y.J.; Li, J.Y. Reactive nanoparticles compatibilized immiscible polymer blends: Synthesis of reactive $\mathrm{SiO}_{2}$ with long poly(methyl methacrylate) chains and the in situ formation of Janus $\mathrm{SiO}_{2}$ nanoparticles anchored exclusively at the interface. ACS Appl. Mater. Interfaces 2017, 9, 14358-14370. [CrossRef]

27. Zhao, X.W.; Wang, H.T.; Fu, Z.A.; Li, Y.J. Enhanced interfacial adhesion by reactive carbon nanotubes: New route to high-performance immiscible polymer blend nanocomposites with simultaneously enhanced toughness, tensile strength, and electrical conductivity. ACS Appl. Mater. Interfaces 2018, 10, 8411-8416. [CrossRef]

28. Fu, Z.A.; Wang, H.T.; Zhao, X.W.; Horiuchi, S.; Li, Y.J. Immiscible polymer blends compatibilized with reactive hybrid nanoparticles: Morphologies and properties. Polymer 2017, 132, 353-361. [CrossRef]

29. Dong, W.Y.; Wang, H.T.; Ren, F.L.; Zhang, J.Q.; He, M.F.; Wu, T.; Li, Y.J. Dramatic improvement in toughness of PLLA/PVDF Blends: The effect of compatibilizer architectures. ACS Sustain. Chem. Eng. 2016, 4, 4480-4489. [CrossRef]

30. Dong, W.Y.; Wang, H.T.; He, M.F.; Ren, F.L.; Wu, T.; Zheng, Q.R.; Li, Y.J. Synthesis of reactive comb polymers and their applications as a highly efficient compatibilizer in immiscible polymer blends. Ind. Eng. Chem. Res. 2015, 54, 2081-2089. [CrossRef]

31. Li, F.; Zhao, X.W.; Wang, H.T.; Chen, Q.; Wang, S.H.; Chen, Z.H.; Zhou, X.Y.; Fan, W.C.; Li, Y.J.; You, J.C. Sub-100 nm cocontinuous structures fabricated in immiscible commodity polymer blend with extremely low volume/viscosity ratio. ACS Appl. Polym. Mater. 2019, 1, 124-129. [CrossRef]

32. Wang, H.T.; Dong, W.Y.; Li, Y.J. Compatibilization of immiscible polymer blends using in situ formed Janus nanomicelles by reactive blending. ACS Macro Lett. 2015, 4, 1398-1403. [CrossRef]

33. Wang, H.T.; Fu, Z.A.; Dong, W.Y.; Li, Y.J.; Li, J.Y. Formation of interfacial Janus nanomicelles by reactive blending and their compatibilization effects on immiscible polymer blends. J. Phys. Chem. B 2016, 120, 9240-9252. [CrossRef] [PubMed]

34. Sundararaj, U.; Macosko, C.W.; Shih, C.K. Evidence for inversion of phase continuity during morphology development in polymer blending. Polym. Eng. Sci. 1996, 36, 1769-1781.

35. López-Barrón, C.R.; Macosko, C.W. A new model for the coarsening of cocontinuous morphologies. Soft Matter 2010, 6, 2637-2647. [CrossRef]

36. You, W.; Yu, W. Control of the dispersed-to-continuous transition in polymer blends by viscoelastic asymmetry. Polymer 2018, 134, 254-262. [CrossRef]

37. Trifkovic, M.; Hedegaard, A.; Huston, K.; Sheikhzadeh, M.; Macosko, C.W. Porous films via PE/PEO cocontinuous blends. Macromolecules 2012, 45, 6036-6044. [CrossRef]

38. Yuan, Z.H.; Favis, B.D. Coarsening of immiscible co-continuous blends during quiescent annealing. AIChE J. 2005, 51, 271-280. [CrossRef]

39. Galloway, J.A.; Jeon, H.K.; Bell, J.R.; Macosko, C.W. Block copolymer compatibilization of cocontinuous polymer blends. Polymer 2005, 46, 183-191. [CrossRef]

40. Sarazin, P.; Favis, B.D. Morphology control in co-continuous poly(l-lactide)/polystyrene blends: A route towards highly structured and interconnected porosity in poly(l-lactide) materials. Biomacromolecules 2003, 4, 1669-1679. [CrossRef]

41. Shao, Y.; Yang, Z.X.; Deng, B.W.; Yin, B.; Yang, M.B. Tuning PVDF/PS/HDPE polymer blends to tri-continuous morphology by grafted copolymers as the compatibilizers. Polymer 2018, 140, 188-197. [CrossRef]

42. Tong, J.; Huang, H.X.; Wu, M. Promoting compatibilization effect of graphene oxide on immiscible PS/PVDF blend via water-assisted mixing extrusion. Compos. Sci. Technol. 2017, 149, 286-293. [CrossRef] 